Dasandara, S.P.M., Kulatunga, U., Ingirige, M.J.B. and Fernando, T., 2021. Climate change challenges facing Sri Lanka: A literature review. In: Sandanayake, Y.G., Gunatilake, S. and Waidyasekara, K.G.A.S. (eds). Proceedings of the $9^{\text {th }}$ World Construction Symposium, 9-10 July 2021, Sri Lanka. [Online]. pp. 183 -195. DOI: https://doi.org/10.31705/WCS.2021.16. Available from: https://ciobwcs.com/papers/

\title{
CLIMATE CHANGE CHALLENGES FACING SRI LANKA: A LITERATURE REVIEW
}

\author{
S.P.M. Dasandara ${ }^{1}$, U. Kulatunga ${ }^{2}$, M.J.B. Ingirige ${ }^{3}$ and T. Fernando ${ }^{4}$
}

\begin{abstract}
The earth's climate has changed throughout history and climate change can be identified as an inevitable phenomenon which is being experienced by the whole world. When considering the Sri Lankan context, it is no different to the global context in that the country's climate has already changed. Sri Lanka, being an island state, is vulnerable to many climate change impacts including high-temperature levels, adverse weather events, sea level rising, and changes in precipitation patterns. The many challenges that arise from these climate-related issues are projected to continue through this century and beyond. Thus, climate change mitigation and adaptation have become the most appropriate ways to restrain these climate change challenges in Sri Lanka. It is paramount to get a broad understanding of how disastrous these climate change challenges are, prior to implementing appropriate responses to overcome them. This urges the need for conducting an in-depth investigation of prevailing climate change challenges in Sri Lanka. Thus, this study presents the prevailing climate change challenges facing Sri Lanka through a conceptual framework, that has been developed based on the existing literature. The developed framework reveals how these prevailing climate changes can lead to a number of challenges. These challenges were identified under three main categories as economic, social, and environmental challenges. The knowledge generated through this literature review will be the focus of future research.
\end{abstract}

Keywords: Climate change; Climate change adaptation; Climate change challenges; Climate change mitigation; Sri Lanka.

\section{INTRODUCTION}

Climate can be identified as a complex and interactive system which consists of the atmosphere, water bodies, land surface, and living beings, etc. (Adedeji et al., 2014). The internal dynamics of the climate system can be significantly influenced by various external factors resulting in a number of changes in the system. The earth's climate has been constantly changing over geological time, contributing to a number of variations all over the world (Esham and Garforth, 2013). Indeed, climate change can be identified as significant fluctuations in the prevailing state of average weather patterns on the planet that last over several decades or longer (Riedy, 2016). In recent decades, climate change has become an alarming issue which is being experienced by the whole world (Esham and Garforth, 2013). More concisely, it can be identified as one of the greatest challenges

\footnotetext{
${ }^{1}$ Department of Building Economics, University of Moratuwa, Sri Lanka, miyamidasandara@gmail.com

${ }^{2}$ Department of Building Economics, University of Moratuwa, Sri Lanka, ukulatunga@uom.lk

${ }^{3}$ School of Science, Engineering and Environment, University of Salford, UK,

M.J.B.Ingirige@salford.ac.uk

${ }^{4}$ School of Science, Engineering and Environment, University of Salford, UK,

T.Fernando@salford.ac.uk
} 
facing humanity in this era (Swim et al., 2011). No country is immune to the impact of climate change (De Costa, 2017) and hence it is imperative to explore the dangerousness of the prevailing and expected climate changes in Sri Lanka in a detailed manner.

When it comes to the Sri Lankan context, the situation is not different to the global context, in that the country has been drastically affected by many climate change challenges (Baba, 2010). The science community in Sri Lanka has shown ample evidence that the country's climate has significantly changed over time (Eriyagama et al., 2010). Although Sri Lanka seems somewhat distant from the other countries in the world, nestling in the midst of the Indian Ocean, it is often regarded as a country predominantly vulnerable to climate changes, as stated by Baba (2010). These climate changes have led to a number of challenges, whereby a spill over effect has occurred mainly on the economic sector, on communities, and on the natural environment of the country (World Bank Group [WBG], 2020). These challenges have created many obstacles with regard to the development of the country; therefore, pertinent actions need to be followed in order to overcome these challenges. In this context, climate change mitigation and adaptation have been acknowledged as the most appropriate ways to counteract these climate change challenges (Hettiaratchi, 2020).

Importantly, it is imperative to know exactly how disastrous these climate change challenges are since such knowledge will directly lead to the successful implementation of responsive actions with regard to climate change. Thus, an in-depth investigation needs to be conducted to explore the prevailing climate change challenges in Sri Lanka. Hence this study aims to comprehend the prevailing climate change challenges facing Sri Lanka. This aim is achieved by developing a conceptual framework based on the existing literature to gain a broad understanding of how disastrous these prevailing climate change challenges could be within the Sri Lankan context.

\section{RESEARCH METHODOLOGY}

An extensive review of literature facilitates the researcher to strengthen the base of the study by gathering prevailing knowledge regarding the research area. Thus, comprehensive literature analysis and arguments were brought to explore the prevailing climate change challenges facing Sri Lanka. In doing so, the deductive approach which begins with the general and ends with the specific was followed. Accordingly, climate change, which is the broad theme of the study was narrow down to the theme of climate change challenges and under that theme, three main categories were derived as economic, social and environmental to explore the challenges. The existing knowledge were obtained through various sources such as journal articles, conference papers, e-books, and other publications. Ultimately, a conceptual framework was developed by compiling the key literature findings to gain a broad understanding of how disastrous these prevailing climate change challenges could be in Sri Lanka.

\section{GLOBAL CLIMATE CHANGE}

In recent decades, climate change has arisen as a growing issue all over the world, adding considerable stress to society and the environment (Adedeji et al., 2014). As per the findings of Riedy (2016), generally, the term "climate change" refers to a change in average weather conditions on the earth that persists over an extended period of time. These changes in climate may be due to natural internal processes within the climate 
system (including volcanic eruptions, solar variations, changes in land surface properties, and the earth's orbital changes) or to human-driven external forces including greenhouse gas emissions from the many human activities such as burning fossil fuels, increasing livestock farming, large scale irrigation and the cutting and burning of forests (Intergovernmental Panel on Climate Change [IPCC], 2007). However, with the rapid developments that have taken place in the world, human-driven or anthropogenic forces have become the key reasons, over the natural processes, for the occurrence of these climate changes today (Swim et al., 2011; Nianthi and Shaw, 2015).

Indeed, a number of devastating impacts can incur on community structures and on ecosystem functions due to these climate changes (Piao et al., 2019). According to Adedeji et al. (2014), the evidence regarding these climate changes is compelling globally, where the precipitation patterns are changing, sea levels are rising, the whole world is getting warmer day by day, and severe weather events such as floods, droughts, storms, etc. are constantly occurring. Added to this, long-term data relating to the fossil records, atmospheric $\mathrm{CO}_{2}$ levels, and the melting glaciers, which have been discovered by the scientists, can also be identified as the signs of global climate change (Warm Heart Worldwide Inc. [WHW], 2020). These impacts of global climate change are getting worse day by day, leading to catastrophic consequences on ecosystems as well as on human wellbeing (Butler, 2018).

\section{IMPACTS OF CLIMATE CHANGE IN SRI LANKA}

Sri Lanka occupies a unique position in the Indian Ocean and, owing to its geographical location, it has become a significantly vulnerable country to climate change, leading to a number of impacts (De Costa, 2017). These impacts mainly include rising temperatures, changes in precipitation patterns, rises in sea level, and an increase in extreme weather events. As stated by Eriyagama and Smakhtin (2010) and Institute of Policy Studies of Sri Lanka [IPS] (2018), in recent times, the intensity and frequency of these extreme weather events due to climate change have increased significantly within the country triggering a large increase in natural disasters. When considering Sri Lanka, floods, landslides, prolonged droughts, coastal erosion, and hazardous heatwaves can be identified as the major natural disasters which can occur due to climate change (Climate Change Secretariat, 2016). 96\% of these natural disasters in Sri Lanka are cause by the adverse impacts of climate change, where the country has become the fourth most climate change affected country in 2016 as per the Global Climate Risk Index (2018).

According to WBG (2020), Sri Lanka, being a tropical country, regularly experiences very high temperatures with an average maximum of $32^{\circ} \mathrm{C}$, where this situation can develop into hazardous heatwaves. Furthermore, Sri Lanka experiences an annual probability of severe droughts of about $4 \%$ as a result of these adverse increases in temperature level. According to Baba (2010), Sri Lanka is mostly impacted by sea-level rises resulting from these thermal expansions, leading to coastal erosion, the intrusion of salinity, and shoreline retreat as the direst consequences. In fact, the study by Han et al. (2010) revealed that Sri Lanka have been faced for many coastal geo-environmental disasters which mainly occur due to the huge thermal expansions resulting from climate changes. Furthermore, Palamakumbure et al. (2020) affirmed in their recent study that gradual and cumulative coastal erosion can be expected in the future within the coastal areas of the country, influencing many geomorphological features such as lagoons, coral reefs, marshlands, sandy ridges, etc. In addition, floods and landslides which occur every 
year can also be identified as other extreme weather events arising from these climate changes (Palliyaguru and Amaratunga, 2008). These predictions are further supported by Eriyagama and Smakhtin (2010) who state that the average rainfall in the country and the intensity of the daily rainfall has increased significantly at many times of the year, triggering a large increase in landslides as well as flood events within the country. They further assert that there are increased occurrences of lightening hazards as well due to the changes in precipitation patterns in many regions of the country. Therefore, it can be seen that many kinds of frightful weather events can occur due to climate change in Sri Lanka and these lead to a number of challenges which are discussed in detail in the next section.

\section{CLIMATE CHANGE CHALLENGES IN SRI LANKA}

As discussed previously, a wide variety of devastating impacts can occur due to climate change in Sri Lanka leading to enormous economic, social and environmental challenges (Yamane, 2009). This means a detrimental effect can occur mainly in the economic sector, in the social wellbeing of the country, and in the natural environment due to these climate-related issues (WBG, 2020). These climate change challenges are broadly visited in the next subsections.

\subsection{ECONOMIC ChALLENGES}

As disclosed by Withanachchi (2019), it is paramount to know how disastrous the impacts of climate change can be on the economy of the country, which is the backbone of the country's development. When considering the economic challenges, many areas can be broadly explored as follows. The agriculture has been played a prominent role in Sri Lankan economy in many ways (United Nations Development Programme [UNDP], 2017). Indeed, it approximately contributes 7\% of the Gross Domestic Product (GDP) of the country, provides $80 \%$ of the domestic food requirement, absorbs $30 \%$ of the labour force, utilizes $43 \%$ of the total land area, and provides the livelihoods for $70 \%$ of the rural population in Sri Lanka (Withanachchi, 2019). At the same time, it is the most sensitive sector with regard to climate change, whereby agricultural production and farm assets have been significantly impacted upon due to the many climate-related hazards during recent years (Climate Change Secretariat, 2016). In this context, it is witnessed that climate change has critically impacted upon the agricultural sector, leaving food production, foreign exchange, and employment at terrible risk. For example, De Costa (2010) has disclosed that both rice and tea production in Sri Lanka is intimately linked with the temperature levels, whereby long term shifts in rainfall patterns and temperature regimes have created substantial damage with regard to national food security, to foreign exchange, and to the livelihoods of the people who depend on such cultivation. According to WBG (2020), many effects such as the impact on water resource availability, soil erosion, alterations in carbon dioxide availability, and the arrival of invasive species can occur due to climate change and resultant weather events, weakening greatly agricultural productivity. At the same time, a notably high dependency of the economy on fisheries can also be identified in Sri Lanka, where the health of the fisheries can be prominently influenced by climate change (WBG, 2020). Rising temperatures and ocean acidification, resulting from the climate changes, have created a significant impact on the fisheries, weakening many areas of the economy. It is evident that fishery stocks, fisheries' habitats and the fish harvesting sector is steadily being impacted upon, as asserted by Arulananthan (2017). 
The tourism industry has also done a remarkable job in leveraging the Sri Lankan economy (Tam, 2019). The same idea was brought forward by Salpage et al. (2019) who stated that Sri Lanka, being an attractive destination for tourists, earns a significant amount of foreign exchange for the national economy through tourism. More importantly, it contributes to nearly $11 \%$ of the country's GDP as the third largest foreign exchange earner in the country (Salpage et al., 2019). In Sri Lanka, the majority of the tourism sector has been established along the coastal zone of the country and the coastal areas have largely been influenced by the adverse impacts of climate change including sea level rises, river flooding, coastal erosion, and extreme rainfall (Tam, 2019). As a result, a spill over effect has occurred on the nature-based tourism in the coastal zone of Sri Lanka.

Moreover, the energy consumption within the country has also prominently risen due to the increase in temperatures (Hettiarachchi et al., 2014). In general, a one-degree increase in the ambient temperature level will lead to a $0.5 \%-8.5 \%$ increase in electricity demand within the country, whereby a significant share of that amount can be identified as being due to the increase in electricity demand associated with rise of temperature due to climate change (WBG, 2020). Although Sri Lanka has abundant energy resources to ensure energy conservation within the country such as solar energy, hydropower and wind power, energy conservation has been critically undermined due to the impact of climate change (Hettiarachchi et al., 2014). Accordingly, high energy consumption can be identified as another key economic challenge that arises due to the impact of climate change.

In contrast, sometimes the aforementioned areas have contributed conversely to the occurrence of climate changes since agriculture, industrial processes and energy production can be identified as the major sources of greenhouse gases in Sri Lanka (Arora, 2019). Thus, it is obvious that the opposing side of the occurrence of a number of challenges on many sectors due to the climate changes (i.e. contribution of many sectors for the occurrence of climate changes) has also happened.

\subsection{Social ChallengeS}

Many of the climate-related issues are likely to disproportionately influence communities in Sri Lanka, leading to a number of short-term and long-term effects (WBG, 2020). As stressed by Withanachchi (2019), the standard of living of people in Sri Lanka has been significantly impacted due to these climate changes and, thereby, the country's economy is also impacted. Agriculturally-based communities in Sri Lanka are vulnerable to many severe weather events including droughts, floods, landslides and increased temperature levels, largely, leaving their livelihoods at greater risk which can impact upon their livelihoods (Esham and Garforth, 2013). Similarly, coastal communities have also been heavily impacted upon due to sea level rises and cyclones resulting from climate changes, as disclosed by Tam (2019). More importantly, these impacts of climate change have tended to enhance societal inequalities, leading to a large increase in poverty within the country (Climate Change Secretariat, 2016). This is mainly because of the direct repercussions on the basic living patterns of the people due to considerable impacts on their settlements and infrastructure. Thus, it can be argued that the living styles of the communities within the country have been enormously impacted upon due to these climate changes. In here also, the opposing side of the occurrence of challenges due to climate changes can be identified (refer Section 5.1), whereby the living patterns of 
people (including many activities such as burning fossil fuels and cutting down forests) have fuelled the occurrence of climate changes (Kottawa-Arachchi and Wijeratne, 2017).

Human health can be identified as another key concern that can be impacted due to climate change. Presently, health impacts (including deaths and disabilities) caused by severe weather events have been reported more frequently than before in Sri Lanka (Madurawala, 2011). As indicated by Cho (2020), the outbreak of many types of diseases can be identified as a crucial problem today in Sri Lanka due to the adverse impacts of climate changes. These health issues include respiratory diseases, allergies, cancers, foodborne diseases, waterborne diseases, and impacts on mental health (Ministry of Health, 2017). At the same time, deaths also can be happened when these health issues have become more critical. Furthermore, problems in accessing safe food and drinking water are also inevitable as the issues that affect human wellbeing due to climate change (Madurawala, 2011). Actually, country's water resources have been noticeably impacted (refer Section 5.3) and food production has been considerably interrupted (refer Section 5.1) due to these climate change impacts. Also, the spreading of kidney disease and incidents of dengue can be regarded as some of the recent examples of major health issues that have arisen in Sri Lanka, mostly as a result of extreme weather events (Cho, 2020). Moreover, as depicted by Ranagalage et al. (2017), most of the urban areas in Sri Lanka have tended to encounter a relatively higher temperature in their surroundings rather than that in rural areas due to the heat island effect as well as thermal expansions arising from climate change (WBG, 2020). Therefore, a number of health issues can occur for people in urban areas due to their exposure to extreme heat. Moreover, sanitation issues and other social problems are significantly unavoidable alongside these adverse impacts of climate change in a country like Sri Lanka which is still developing. As stated by the World Health Organization [WHO] (2015), the risk of spreading different types of diseases in Sri Lanka will largely increase towards 2070 with the prolonged exposure to the extreme impacts of climate change.

In this context, it can be argued that a huge impact has occurred with regard to the social wellbeing of the country due to climate change.

\subsection{ENVIRONMENTAL ChALLENGES}

To date, climate change has adversely impacted upon the natural environment, altering many natural systems connected to the eco-systems, the water cycles and the biodiversity of Sri Lanka (Eriyagama and Smakhtin, 2010). Many ecosystem services, which are indispensable for the existence of human beings, have heavily declined as a result of these impacts on the environment.

Water resources can be identified as a crucial part of the environment as they fuel domestic activities, agricultural activities, many industrial activities, and also provide a significant share of power generation within the country (Eriyagama et al., 2010). Furthermore, besides fulfilling the needs of human beings, the survival of all ecosystems mainly relies on water resources. Although various water resources can be seen in Sri Lanka based on its topography, the availability, supply, distribution, use and conservation of these water resources mainly depend on the climatic conditions of the country (Climate Change Secretariat, 2016). Hence, these water resources can be largely impacted upon due to the catastrophic effects of climate change on the country. As identified by Eriyagama et al. (2010), groundwater can be polluted and water resources can be reduced in many areas of the country, leaving the quality and quantity of the country's water 
resources at huge risk. Being a tropical country, the lack of drinking water has become the biggest issue in many areas in Sri Lanka, more so than ever before, which is being steadily amplified due to the recent droughts resulting from climate change (Cho, 2020).

Sri Lanka currently enjoys a rich and unique diversity of fauna and flora, providing many economic and environmental benefits (Kottawa-Arachchi and Wijeratne, 2017). However, the biodiversity of these ecosystems has significantly changed and has been reduced due to the impacts of climate change. As noted by the National Oceanic and Atmospheric Administration [NOAA] (2019), the natural habitats of species are being changed and modified, while the timing of natural events (such as flowering and egglaying) are shifting considerably, altering the life patterns of many species in a negative manner. The temperature level of the ecosystems in urban areas can be vastly increased due to climate change coupled with the urban heat island effect, as discussed in section 5.2. Sri Lanka has a biologically rich and diversified coastal environment with unique ecosystems (such as beaches, lagoons, marshlands, bays, sand dunes) and a variety of water bodies (Climate Change Secretariat, 2016). All these ecosystems have been affected significantly due to sea level rise, coastal erosion, inundation, and the many other impacts of climate change. Furthermore, the ocean has become more acidic with the absorption of nearly $30 \%$ of the $\mathrm{CO}_{2}$ released into the atmosphere, leaving marine life in great danger (NOAA, 2019). Accordingly, it is obvious that the natural environment has also been crucially affected by the adverse impacts of climate change in Sri Lanka, creating many challenges.

Overall, the impacts of climate change in Sri Lanka are widespread and they have created a number of social, economic, and environmental challenges which are increasing day by day. Therefore, appropriate actions need to be taken by respective parties in order to overcome the aforementioned climate change challenges. In this context, climate change adaptation and mitigation have become appropriate ways to withstand the prevailing climate change challenges, as discussed in the next section.

\section{CLIMATE CHANGE MITIGATION AND ADAPTATION}

When it comes to combating the climate change challenges, mitigation and adaptation have been acknowledged as a crucial activity (United Nations Educational Scientific and Cultural Organization [UNESCO], 2019). Climate change mitigation refers to altering the proximate causes for climate changes directly or indirectly to limit the extent of climate change (Swim et al., 2011). That means, it includes the actions taken to reduce and curb the causes of climate change. According to Mertz et al. (2009), climate change adaptation can be broadly explained as making adjustments by social, economic and ecological systems to reduce their vulnerability to the actual, as well as expected, climate change challenges. They further elaborated that climate change adaptation mainly comprises actions which need to be performed to reduce vulnerability or to enhance resilience. Accordingly, it is apparent that mitigation addresses the causes of climate change, while adaptation attempts to address its impacts, as noted by UNESCO (2019). As noted by Yamane (2009), sometimes the impacts of climate changes appear unescapable even with the mitigation strategies. Hence, many scientists and other relevant parties have been focusing their attention on implementing climate change adaptation as an alternative or supplementary strategy to mitigation measures (Yamane, 2009). To date, a wide range of actions have been undertaken in this direction throughout the world to reduce adverse climate change challenges. Paris Climate Change Agreement which was 
established in 2015, Sendai Framework for Disaster Risk Reduction, which was adopted for the period of 2015-2030, and Cancun Adaptation Framework, which was adopted in 2010 can be regarded as some examples for those climate change mitigation and adaptation actions (Hewawasam and Matsui, 2019; Kelman, 2015).

When considering the Sri Lankan context, mitigation and adaptation for the constantly happening climate changes has become an urgent need for the country in order to overcome the identified climate change challenges. In Sri Lanka, a significant contribution can be identified in the implementation of climate change mitigation through a number of actions and plans (Climate Change Secretariat, 2016). For instance, the Ministry of Environment, with the collaborative efforts taken by Climate Change Secretariat, have implemented a Technology Needs' Assessment (TNA) and a National Climate Change Policy including many policy statements to cover climate change mitigation. Further, many programmes like the Haritha Lanka Programme have targeted many strategies and actions as climate change mitigation measures to cope with prevailing and expected climate change challenges (Hewawasam and Matsui, 2019).

When considering adaptation, the successful implementation of climate change adaptation in Sri Lanka would mainly have to take account of the country's vulnerability to climate change and its adaptive capacity (Climate Change Secretariat, 2016). Many significant gaps and barriers can be identified in the country's adaptive capacity which mainly includes knowledge and skills, technologies, information, and livelihood assets, as further stated by the Climate Change Secretariat study. Thus, there is a crucial requirement to bolster the adaptive capacity of the country towards successful climate change adaptation. Presently, many initiatives have taken steps to implement climate change adaptation in Sri Lanka in order to respond to the adverse impacts of climate change (Eriyagama and Smakhtin, 2010; Hewawasam and Matsui, 2019)). These initiatives have been formulating and implementing different types of policies and plans as the adaptation responses by reducing vulnerability and enhancing resilience. The National Environment Policy (NEP), the National Climate Change Policy of Sri Lanka, the National Agriculture Research Policy, the National Adaptation Plan (NAP) for Climate Change Impacts in Sri Lanka and the National Policy on Disaster Management can be identified as some examples of such policies for climate change adaptation in Sri Lanka (Hewawasam and Matsui, 2019; WBG, 2020). Added to this, a Clean Development Mechanism (CDM) policy and a few CDM projects have also been implemented in Sri Lanka to reduce greenhouse gas emissions into the atmosphere (Eriyagama and Smakhtin, 2010). Also, the adoption of Nationally Determined Contributions (NDCs) for climate change mitigation and adaptation under the Paris Agreement in 2016 can be regarded as a foremost commitment in this direction (Hewawasam and Matsui, 2019).

In this context, it is obvious that somewhat stable and persistent support has gained from the policymakers and other relevant parties for the implementation of climate change policies and plans in Sri Lanka to cope with the adverse impacts of climate changes. Those parties need to be further encouraged to strengthen the inclusion of climate change considerations into prevailing, as well as new, policies and plans for the successful implementation of climate change mitigation and adaptation in Sri Lanka (UNDP, 2017). 


\section{THE CONCEPTUAL FRAMEWORK}

The previous sections discussed the threat of climate change (which has now become a severe crisis in Sri Lanka) by identifying the impacts of climate change and the resulting challenges. Furthermore, climate change mitigation and adaptation were identified as appropriate ways of overcoming those challenges. A broad understanding of how disastrous these climate change challenges are within the Sri Lankan context can be illustrated through a conceptual framework, as shown in Figure 1.

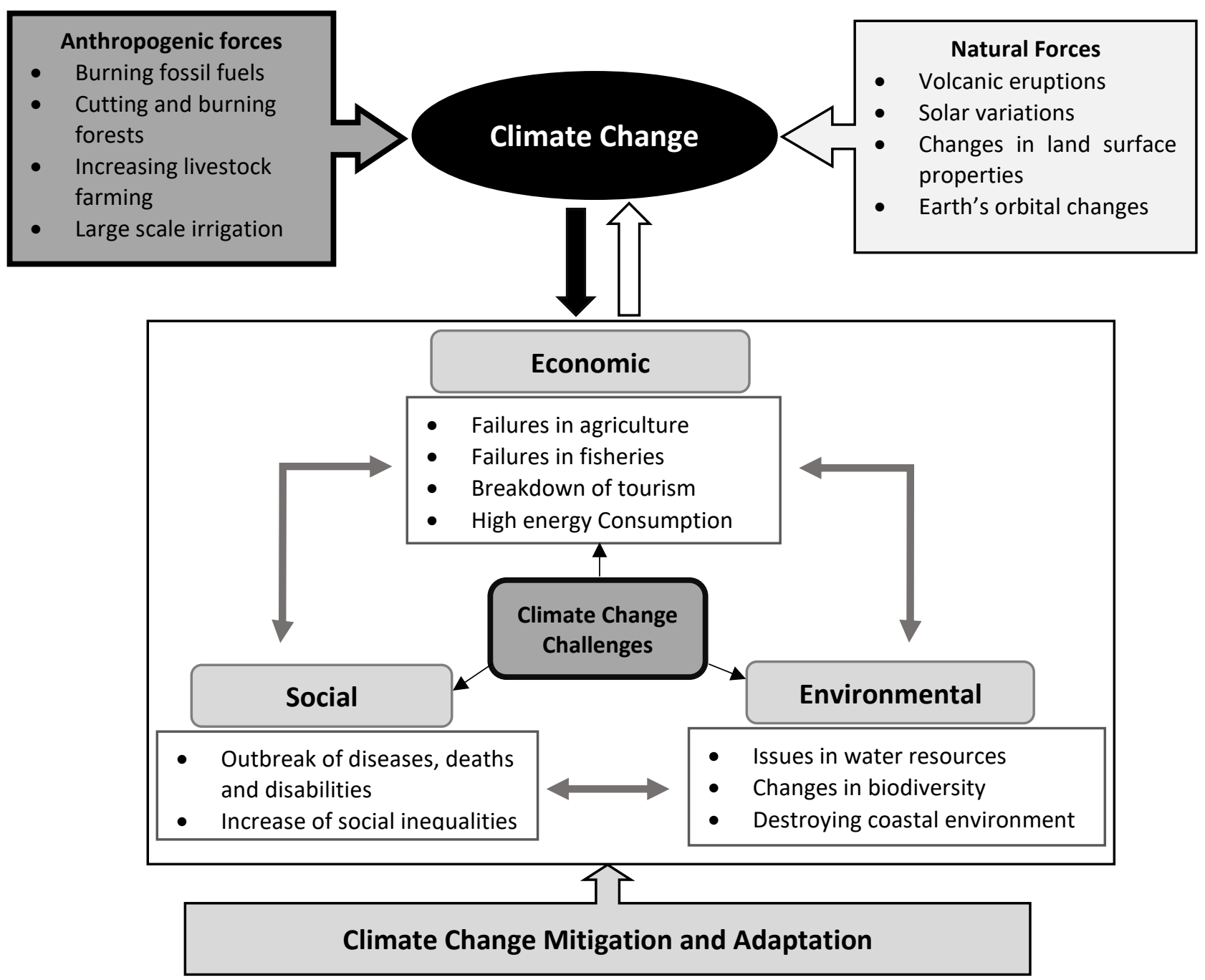

Figure 1: Conceptual framework

As depicted in this framework, changes in weather conditions can occur due to many reasons which can be identified as natural forces and anthropogenic or human-driven forces. Among these two categories of reasons, because of rapid developments, humandriven forces have become the key reasons for the occurrence of these climate changes in Sri Lanka today as highlighted in this framework. Accordingly, many challenges can incur significantly due to the devastating impacts of climate changes. As presented in this framework, those challenges can be identified under three main categories namely, economic, social, and environmental challenges which means that the country's economy, communities, and the natural environment are the areas that are strongly affected by climate change. The main vulnerable areas under each category are also 
presented in this framework in order to gain a broad understanding of how disastrous these climate change challenges can be/are. Further, these three main categories of challenges are strongly interconnected where the challenges of one category can highly relates with the challenges of another category. It was clearly presented by using two point arrows in the framework. For example, failures in agriculture, which is an economic challenge can be a reason for the increase of social inequalities which is a social challenge. Also, issues in water resources, which is an environmental challenge can be a social challenge as well since it leads to many diseases for the communities sometimes. In contrast, some of these areas have provided a significant contribution to the occurrence of climate change in some situations. For example, while climate change has impacted on the effectiveness of the areas of tourism, agriculture, fisheries, energy consumption and the living patterns of people, these areas have also influenced, conversely, to the occurrences of climate change. This is clearly shown in the framework by using two arrows, whereby the black arrow represents the impact of climate change in many areas and the white arrow represents the contribution of some areas towards climate change. Finally, as discussed in Section 5 of this paper, climate change mitigation and adaptation are regarded as the appropriate ways of overcoming the identified climate change challenges which are already happening, and will happen in the future, in Sri Lanka.

\section{CONCLUSIONS AND THE WAY FORWARD}

This extensive review of the literature is intended to comprehend the prevailing climate change challenges facing Sri Lanka in a detailed manner since it is beneficial to get a broad understanding of how disastrous these challenges are/can be prior to the implementation of mitigation and adaptation responses to overcome them. According to the existing literature, it is evident that climate change, which is mainly man-induced, has become one of the biggest problems facing mankind in this era. Generally, climate change can be identified as changes in the average weather conditions of the planet which last over an extended period of time. These anticipated changes in climate mainly include changes in precipitation patterns, higher temperatures and changes in the occurrence of weather events such as floods, droughts, landslides, storms, etc. The impacts of these climate changes have created catastrophic consequences on ecosystem functions as well as on human civilisation, resulting in enormous climate change challenges. These climate change challenges in Sri Lanka have been identified in a broader view in this paper under three main categories, namely economic, social and environmental challenges. Furthermore, a deep insight into each category of challenges was discussed comprehensively, as per the prevailing literature. The influence on agriculture and fisheries, the tourism sector, and the energy consumption within the country were investigated under the economic challenges, while the impact on living patterns of the people and the health of the communities were discussed under the social challenges. Similarly, environmental challenges were emphasised with relevance to the impact on water resources, biodiversity, and the coastal environment of the country. Accordingly, it was proven that a number of challenges can be identified which are already occurring, and will occur in the future, due to the adverse impacts of climate change in Sri Lanka.

These challenges can be overcome significantly by implementing climate change mitigation and adaptation responses and many initiatives have already been undertaken within the country in this direction. The findings generated through this study can assist policymakers and other relevant parties in obtaining a broad understanding with regard 
to the prevailing as well as expected climate change challenges in Sri Lanka, leading towards the successful implementation of climate change mitigation and adaptation measures. Furthermore, this paper is an initial conceptualisation of an investigation on the climate change challenges facing Sri Lanka whereby the findings will contribute to a roadmap on implementing climate change policies with regard to climate change adaptation in Sri Lanka as a way forward of this paper.

\section{ACKNOWLEDGEMENTS}

This work was supported by the Global Challenges Research Fund (GCRF) and the Economic and Social Research Council (ESRC) under the Grant ES/T003219/1 entitled "Technology Enhanced Stakeholder Collaboration for Supporting Risk-Sensitive Sustainable Urban Development".

\section{REFERENCES}

Adedeji, O., Reuben, O. and Olatoye, O., 2014. Global climate change. Journal of Geoscience and Environment Protection, 2, pp. 114-122.

Arora, N.K., 2019. Impact of climate change on agriculture production and its sustainable solutions. Environmental Sustainability, 2, pp. 95-96.

Arulananthan, K., 2017. Climate change research on fisheries and aquaculture: a review of current status. In: Marambe, B. (ed.) Proceedings of the Workshop on Present Status of Research Activities on Climate Change Adaptations, Colombo: Sri Lanka Council for Agricultural Research Policy, pp. 121-126.

Baba, N., 2010. Sinking the pearl of the indian ocean: Climate change in Sri Lanka. Global Majority EJournal, 1(1), pp. 4-16.

Butler, C.D., 2018. Climate change, health and existential risks to civilization: A Comprehensive Review ( 1989-2013 ). International Journal of Environmental Research and Public Health, 15, pp. 1-21.

Cho, H., 2020. Climate change risk assessment for Kurunegala, Sri Lanka: Water and heat waves. Climate, 8(12), p.140.

Climate Change Secretariat, 2016. National Adaptaion Plan for Climate Change Impacts in Sri Lanka. Colombo. Available from: https://www4.unfccc.int/sites/NAPC/Documents NAP/National Reports/National Adaptation Plan of Sri Lanka.pdf.

De Costa, J., 2017. Climate Change In Sri Lanka : Myth or reality? Evidence from long-term meteorological data. Journal of the National Science Foundation of Sri Lanka, 36, pp. 63-88.

De Costa, W.A.J.M., 2010. Adaptation of agricultural crop production to climate change: A policy framework for sri lanka. Journal of the National Science Foundation Sri Lanka, 38(2), pp. 79-89.

Eriyagama, N., Smakhtin, V., Chandrapala, L. and Fernando, K., 2010. The impacts of climate change on water resources and agriculture in Sri Lanka: A review and preliminary vulnerability mapping. Colombo: International Water Management Institute.

Eriyagama, N. and Smakhtin, V., 2010. Observed and projected climatic changes, their impacts and adaptation options for Sri Lanka : A review. In Conference: International Water Management Institute, pp. 99-117.

Esham, M. and Garforth, C., 2013. Agricultural adaptation to climate change: insights from a farming community in Sri Lanka. Mitigation and Adaptation Strategies for Global Change, 18(5), pp.535-549.

Han, W., Meehl, G., Rajagopalan, B., Fasullo, J., Hu, A., Lin, J., Large, W., Wang, J., Quan, X.W., Trenary, L.L., and Walkraf, A., 2010. Patterns of indian ocean sea-level change in a warming climate. Nature Geoscience, 3(8), pp. 546-550.

Hettiarachchi, S.S.L., Goonasekera, H., Gunathilake, S. and Weeresinghe, S., 2014. An investigation into societal challenges of Sri Lanka with a focus on National Planning and Coordination. Procedia Economics and Finance, 18, pp. 795-801.

Hettiaratchi, V., 2020. Influencing green: Climate change, state policy and civil society. Lund University. 
Hewawasam, V. and Matsui, K., 2019. Historical development of climate change policies and the climate change secretariat in Sri Lanka. Environmental Science and Policy, 101, pp. 255-261.

Institute of Policy Studies of Sri Lanka [IPS], 2018. Sri Lanka: State of the economy 2018. Sri Lanka.

Intergovernmental Panel on Climate Change [IPCC], 2007. IPCC fourth assessment report: Climate change.

Kelman, I., 2015. Climate change and the sendai framework for disaster risk reduction. International Journal of Disaster Risk Science, 6, pp. 117-127.

Kottawa-Arachchi, J.D. and Wijeratne, M.A., 2017. Climate change impacts on biodiversity and ecosystems in Sri Lanka: A review. Nature Conservation Research, 2(3), pp. 2-22.

Madurawala, S., 2011. Climate change and human health: Is Sri Lanka ready to face the challenge?, Health Economic Policy Unit of the IPS.

Mertz, O., Halsnaes, K. and Olesen, J.E., 2009. Adaptation to climate change in developing countries. Environmental Management (2009), 43, pp. 743-752.

Ministry of Health, 2017. Health impacts of climate change. Colombo. Available from: http://www.epid.gov.lk/web/images/pdf/wer/2017/vol_44_no_16-english.pdf.

National Oceanic and Atmospheric Administration [NOAA], 2019. Climate change impacts. Available from: https://www.noaa.gov/education/resource-collections/climate/climate-change-impacts.

Nianthi, K.W.G.R. and Shaw, R., 2015. Climate change and its impact on coastal economy of Sri Lanka. The Global Challenge, pp. 1-21.

Palamakumbure, L., Ratnayake, A.S., Premasiri, R., Ratnayake, N., Katupotha, J., Dushyantha, N., Weththasinghe, S. and Weerakoon, P., 2020. Sea-Level Inundation And Risk Assessment Along The South And Southwest Coasts Of Sri Lanka. Geoenvironmental Disasters, 7(17).

Palliyaguru, R. and Amaratunga, D., 2008. Managing disaster risks through quality infrastructure and vice versa. Structural Survey, 26(5), pp. 426-434.

Piao, S., Liu, Q., Chen, A., Janssens, I.A., Fu, Y., Dai, J., Liu, L., Lian, X., Shen, M. and Zhu, X., 2019. Plant phenology and global climate change: Current progresses and challenges. Global Change Biology, 25(6), pp. 1922-1940.

Ranagalage, M., Estoque, R.C. and Murayama, Y., 2017. An urban heat island study of the Colombo metropolitan area, Sri Lanka, based on Landsat data (1997-2017). ISPRS International Journal of GeoInformation, 6(7).

Riedy, C., 2016. Climate change, In Ritzer, G. (ed.) Blackwell Encyclopedia of Sociology. Blackwell.

Salpage, N.D., Aanesen, M. and Amarasinghe, O., 2019. Is the Sri Lankan ecotourism industry threatened by climate change? A case study of Rekawa coastal wetland using contingent visitation approach. Environment and Development Economics, 25(3), pp. 226-243.

Swim, J.K., Stern, P.C., Doherty, T.J., Clayton, S., Reser, J.P., Weber, E.U., Gifford, R. and Howard, G.S., 2011. Psychology's contributions to understanding and addressing global climate change. American Psychologist, 66(4), pp. 241-250.

Tam, S., 2019. Sounding the alarm: Is the Sri Lankan tourism sector prepared for climate change? University of Waterloo.

United Nations Development Programme [UNDP], 2017. The economics of climate change adaptation programme in Asia and the Pacific [Online], Available from: https://www.adaptationundp.org/projects/economics-climate-change-adaptation-programme-asia-and-pacific

United Nations Educational Scientific and Cultural Organization [UNESCO], 2019. Climate change mitigation and adaptation - Simple guide to schools in Africa. Nairobi, Kenya: East Africa Regional Office, Kenya.

United Nations Framework Convention on Climate Change [UNFCCC], 2021. What do adaptation to climate change and climate resilience mean? [Online], Available from: https://unfccc.int/topics/adaptation-and-resilience/the-big-picture/what-do-adaptation-to-climatechange-and-climate-resilience-mean\#: :text=Adaptation refers to adjustments in,opportunities associated with climate change. 
Warm Heart Worldwide Inc. [WHW], 2020. Climate change primer. [Online] Available from: https://warmheartworldwide.org/climatechange/?gclid=CjwKCAiAhbeCBhBcEiwAkv2cY6SScZy_D yD7rdicYqKSSPOd4u4BhoKLhI96jpO1XvrjQckFG2z0SRoCipMQAvD_BwE.

Withanachchi, A., 2019. Here's how climate change will impact you. [Online]Available from: https://www.lk.undp.org/content/srilanka/en/home/blog/2019/03/22032019.html.

World Bank Group [WBG], 2020. Climate risk country profile. Washington. [Online] Available from: https://www.adb.org/sites/default/files/publication/653586/climate-risk-country-profile-sri-lanka.pdf.

World Health Organization [WHO], 2015. Climate and health country profile 2015 - Sri Lanka demographic estimates. [Online] Available from: http://www.climatechange.lk/adaptation/Files/Strategy_Booklet-Final_for_Print_Low_res.

Yamane, A., 2009. Climate change and hazardscape of Sri Lanka. Environment and Planning, 41, pp. 23962416. 